\title{
What does stakeholder involvement mean for fisheries management?
}

\author{
$\underline{\text { Margrethe Aanesen }}{ }^{1}$, Claire W. Armstrong ${ }^{1}$, Helen J. Bloomfield ${ }^{2}$ and $\underline{\text { Christine Röckmann }}^{3}$
}

\begin{abstract}
The Common Fisheries Policy (CFP) sets the guidelines for the management of European fisheries. The CFP is revised every 10 years, and the last two revisions have laid the groundwork for extending stakeholder participation in European Union fisheries management. The fishery industry and nongovernmental organization (NGOs) especially are recommended to be given greater influence. In this paper we report results from an international survey on fisheries stakeholders' preferences for the three pillars of sustainable fisheries activities as defined in the CFP: ecological, economic, and social. Results of the survey show that industry member preferences were significantly different from the preferences of authorities, scientists, and NGOs. The preferences of the three latter groups did not vary significantly across stakeholder group. This raises the question of what consequences the planned stakeholder involvement in the CFP may have, given the preferences revealed in our survey.
\end{abstract}

Key Words: fisheries management; stakeholder involvement; stakeholder preferences

\section{INTRODUCTION}

There is a growing commitment to an ecosystem approach (EA) when managing natural marine resources to address society's multiple objectives for the marine environment (Rice 2011, Röckmann et al. 2015). The concept of an EA is derived from the 1992 Convention on Biological Diversity and the subsequent 2002 World Summit on Sustainable Development, and underlies an increasing number of international policies for managing the marine environment, such as Canada's Oceans Act in 1997, Australia's Oceans Policy in 1998, Europe's Integrated Maritime Policy in 2007, and the U.S. National Oceans Policy in 2010. Key advantages of an EA over other approaches to natural resource management include its requirement to integrate ecological, social, and economic considerations, and the recognition that people are an integral component of ecosystems and should be in involved in the application of an EA (Röckmann et al. 2015).

These requirements have been recognized in Europe 's recently reformed Common Fisheries Policy (CFP), which seeks to achieve sustainable exploitation of Europe's marine biological resources through management guided by the principles of good governance including decision making based on "broad involvement of stakeholders at all stages of the policy from conception to implementation" (EU 2002:3) Sustainable exploitation requires consideration of ecological, economic, and social components of the ecosystem. Ecological sustainability means prevention of overfishing and depletion of commercial stocks; economic sustainability aims to ensure an efficient harvest, i.e., one may not apply more input than necessary for a given harvest size; and social sustainability aims to ensure that the fisheries' activities form an integral part of the economic activities in the local community (EU 2002). However, interpretation and realization of each of the pillars, and thus the relative weight applied to them in decision making and the resultant management, are not straightforward and may vary at the most fundamental level because of differences in interpretation of the term "sustainability," e.g., focus on ecosystem health, economic opportunities, or human well-being, or a combination thereof (Leslie and McLeod 2007), and the priorities of the different stakeholders involved in the decision-making process.
Identification of stakeholders for involvement in the management process is not a straightforward task, and various definitions exist in the fishery context. Townsley (1998) and Mackinson et al. (2011) distinguish between primary, i.e., principal, and secondary, i.e., other, stakeholders: primary stakeholders encompass fishers and their representative organizations; and secondary stakeholders include those with a more indirect interest in the fisheries, such as institutions and agencies concerned with managing the resource, civil society organizations, and dependent industries. The CFP identifies the following stakeholder groups as ones that should be consulted about the adoption of management plans: advisory councils, consisting of the fishing industry and nongovernmental organizations (NGOs), evolved from the Regional Advisory Councils (RACs) established under the 2002 reform of the CFP; operators in the fishing industry; scientists; and other stakeholders having an interest in management of fisheries (EU 2013).

In this study, we build on the CFP groupings, adopting a more generic definition of a stakeholder as a person who has a stake in fisheries and/or their management and who affects and/or can be affected by actions taken by themselves or others that impact the fisheries. In the context of managing European Union (EU) fisheries, we identified the most important stakeholder groups as (1) the top of the decision-making tree in top-down governance structures, consisting of administrative entities, which encompass the European Commission and national authorities such as managers and policy makers; (2) the scientists who provide management advice, based both on biological status of the commercial stocks and social considerations such as employment; (3) the stakeholder groups with an economic interest in fisheries activities including fishers, fishers' organizations, fishing companies, the processing industry, and marketing and export organizations; and (4) civil society organizations, including environmental nongovernmental organizations (ENGOs), e.g., bird or whale watchers, and the more traditional ENGOs such as Greenpeace and World Wildlife Fund, which have over recent decades taken an increased interest in the impacts of fisheries activities (Mardle et al. 2004, Hatchard 2005, Nielsen and Mathiesen 2006). The general public may also have interest in 
fisheries, but we assumed that they would have to form pressure groups and thus be a part of the ENGOs to have any effect on fishing activities. Other sectors such as tourism and energy, e.g., oil and gas, and renewables may also have an interest in the spatial management of fishing activities, particularly given the requirement of a true EA to implement cross-sector management, but are not included in the key stakeholder groups because of a single-sector focus on fisheries.

During the last two reform processes of the CFP, undertaken in 2002 and 2012, the role of stakeholders has shifted "from a traditionally linear science-policy interface towards a more interactive governance system that involves actors beyond scientists and policy makers" (Link 2012:337). What does this imply for the realization of the objectives in the new CFP? Different stakeholders can have different preferences, so the concrete implementation of objectives depends on the influence these stakeholders have in the new policy process(es).

As a consequence of the 2002 reform of the CFP, RACs based on the five large EU sea areas were established: Baltic Sea, North Sea, Mediterranean Sea, North Western Waters, and South Western Waters. In addition, a RAC for pelagic stocks and a RAC for the high-seas/long-distance fleet were established (Council of the European Union 2004). This can be seen as an effort to involve representatives from a broader set of stakeholders, because the RACs consist of representatives from industry, i.e., the fisheries sector, and civil society organizations, i.e., other interest groups affected by the CFP. Scientists may be invited as experts, and representatives from the Commission of European Communities and national and regional authorities, among others, may be invited as active observers. The RACs' tasks are to provide recommendations and suggestions regarding issues relevant for their sea area, fishery, or fleet (Council of the European Union 2004). The 2012 reform reinforces the participation aspect in that it raised the issue of giving the industry in particular more responsibility for the implementation of the CFP (Commission of European Communities 2009).

There are good reasons for including stakeholders in the fisheries management process. First, local ecological knowledge can complement limited scientific information; thus, the participation of new stakeholders in the management process can improve the knowledge base (Berkes et al. 2000, Davis and Wagner 2003, Wieber et al. 2004, Gassalla and Diegues 2011, Linke et al. 2011, Röckmann et al. 2012, Haapasaari et al. 2013) and reveal new information to the regulators. Second, including stakeholders in management is expected to increase the legitimacy of the management by creating understanding and support among the stakeholders for the management measures such as new regulations (Raakjær and Vedsmand 1995, Degnbol et al. 2006, de Vos and Tatenhove 2011, Haapasaari et al. 2013). Third, when taking a utilitarian perspective, in which society's welfare function is the aggregate of individual utility functions, it is a precondition for maximizing social welfare to include stakeholders representing various preferences about a managed resource.

In this paper we explore predefined stakeholder groups' preferences for the three pillars of sustainable fisheries activities, i.e., ecological, economic, and social, by assessing (1) differences in the stakeholder groups' preferences and (2) diversity in the preferences within the stakeholder groups. Can we presuppose that individual stakeholders belonging to a particular predefined group will have similar preferences regarding, for example, the interpretation and weighting of the three pillars of sustainability in the CFP and that these preferences will vary across stakeholder groups?

There is debate in the literature on whether stakeholder group is a significant background variable for explaining differences in individuals' preferences for fisheries objectives. Wattage et al. (2005) and Mardle et al. (2004) utilized the same data set, based on 24 completed responses from stakeholders belonging to the UK fisheries of the English Channel representing 4 "natural groups": administration/management, the catching sector, ENGOs, and scientific/industry bodies. Stakeholders in both studies were asked to prioritize between the following three overarching objectives: (1) conservation of the fishery and marine environments, (2) improvement of the fishery socioeconomic structure, and (3) reduction of conflict within the fishery. Wattage et al. (2005) used a choice experiment, whereas Mardle et al. (2004) applied the analytical hierarchy process (AHP). Both approaches demonstrated that maintaining regional employment, a subcategory under objective 2, was of greatest importance, followed by sustainable commercial stocks, a subcategory under objective 1, and that this ranking was uniform across all stakeholder groups.

Nielsen and Mathiesen (2006) and Pascoe et al. (2009) each also used the AHP approach on their own data sets. Nielsen and Mathiesen (2006) included 12 stakeholder groups: 3 groups representing the harvest sector, 1 group representing the processing industry, 2 groups representing national administration, 1 group each representing trade union and scientists, and 4 groups representing ENGOs; of these, 9 were domestic, i.e., Danish, and 3 foreign, i.e., United Kingdom, in their study of management preferences in the industrial fisheries for Norwegian pout (Trisopterus esmarkii) and sandeel (Ammodytes marinus) in Denmark. They considered economic, political, and biological interests, and demonstrated that the harvest, processing, and trade union stakeholder groups scored economic interests as most important; all other Danish stakeholders scored highest on biological interests. Only the UK national administration scored highest on the political interest, which was to ban all fisheries for nonhuman consumption, meaning the industrial fisheries serving the plants producing fish oil and fish flour.

Pascoe et al. (2009) used a similar framework in a study of fisheries management in Australia. Their study considered management objectives of (1) enhancing economic performance; (2) ensuring resource sustainability; (3) minimizing environmental impacts; and (4) minimizing externalities, defined as unintended effects of the fishing activities, e.g., bycatches. They interviewed 74 stakeholders including government officials, industry representatives, scientists, and conservation groups and found that scientists and the management stakeholders scored highest on the sustainability objective (objective 2) and lowest on externalities (objective 4); economists and industry stakeholders scored highest on the economic objective (objective 1); and ENGOs and recreational stakeholders scored highest on environmental impacts (objective 3). Crucially, large variance in stakeholder preferences within predefined stakeholder groups has been found (Mardle et al. 2004, Wattage et al. 2005; Pascoe et al. 2009). Pascoe et al. (2009) 
concluded that the observed lack of coherence of preferences within predefined stakeholder groups implied that management decisions made with stakeholder input may be more dependent on the set of individuals participating in the management process rather than the composition of the stakeholder groups represented.

de Nooy (2013) concluded that there were significant differences between stakeholder groups when it came to knowledge and values regarding fisheries activities, highlighting particular differences between industry and other stakeholder groups in the management of the Baltic salmon. Clearly, stakeholders have diverse knowledge, values, and preferences in relation to use and management of resources. The survey encompassed 85 respondents from 8 European countries drawn from the 4 predefined stakeholder groups, defined by professional affiliation.

\section{METHODS AND DATA}

\section{A three-layer hierarchical tree describing aspects of fisheries activities}

As part of the Making European Fisheries Ecosystem Plans Operational (MEFEPO) project, a process was implemented during which representatives from the eight countries involved in the project, Denmark, France, Ireland, the Netherlands, Norway, Portugal, Spain, and the United Kingdom, participated in three workshops. As part of these workshops the three pillars of sustainable fisheries activities, ecological, economic, and social, were interpreted and made concrete and measurable in the following way: Each pillar was assigned two to four descriptors, which were attempts to describe the most important aspects of that pillar, and the descriptors were in turn made operational by assigning each descriptor one indicator that could be quantitatively measured. Figure 1 shows the three-layer hierarchy, consisting of (1) the three pillars of sustainable fisheries management; (2) descriptors that interpret, limit, and make concrete the pillars; and (3) indicators aimed at making the descriptors measurable. Our method was inspired by the 11 descriptors for Good Environmental Status of the marine environment, as listed in the EU Marine Strategy Framework Directive. The ecological pillar is made up of four Marine Strategy Framework Directive descriptors that are considered to be affected by fisheries: biodiversity, commercial fish and shellfish, food web, and sea floor integrity. Two descriptors, efficiency and stability, were chosen for the economic pillar and three, community viability, job attractiveness, and food security, were chosen for the social pillar. The job attractiveness indicator is not the same as the much-applied indicator job satisfaction. Job attractiveness indicates to what degree the fisheries sector is sufficiently attractive to recruit competent employees. Each descriptor has at least one indicator (Piet et al. 2011).

An initial draft of the hierarchical tree (Fig. 1) was prepared by project members. Subsequently, it was discussed and modified in an iterative and collaborative process with the fisheries stakeholders.

\section{The process and the participating stakeholders}

In total about 80 fisheries stakeholders participated in three workshops, including the project members. Following Townsley (1998) and Mackinson et al. (2011), we used the broad definition of stakeholders, encompassing fishers as well as those with a more indirect interest in the fisheries, such as national and EU authorities, ENGOs, and scientists. We predefined four stakeholder groups to ensure that the project was able to explore the ecological, economic, and social aspects of fisheries management as stated in the CFP: (1) policy, i.e., national and EU-level fisheries authorities; (2) scientists, i.e., fisheries biologists, economists, and other social scientists; (3) industry, i.e., individual fishers and regional and national fishers' organizations; and (4) NGOs, i.e., environmental and other NGOs.

Fig. 1. Systematic description of preferences concerning fisheries activities.

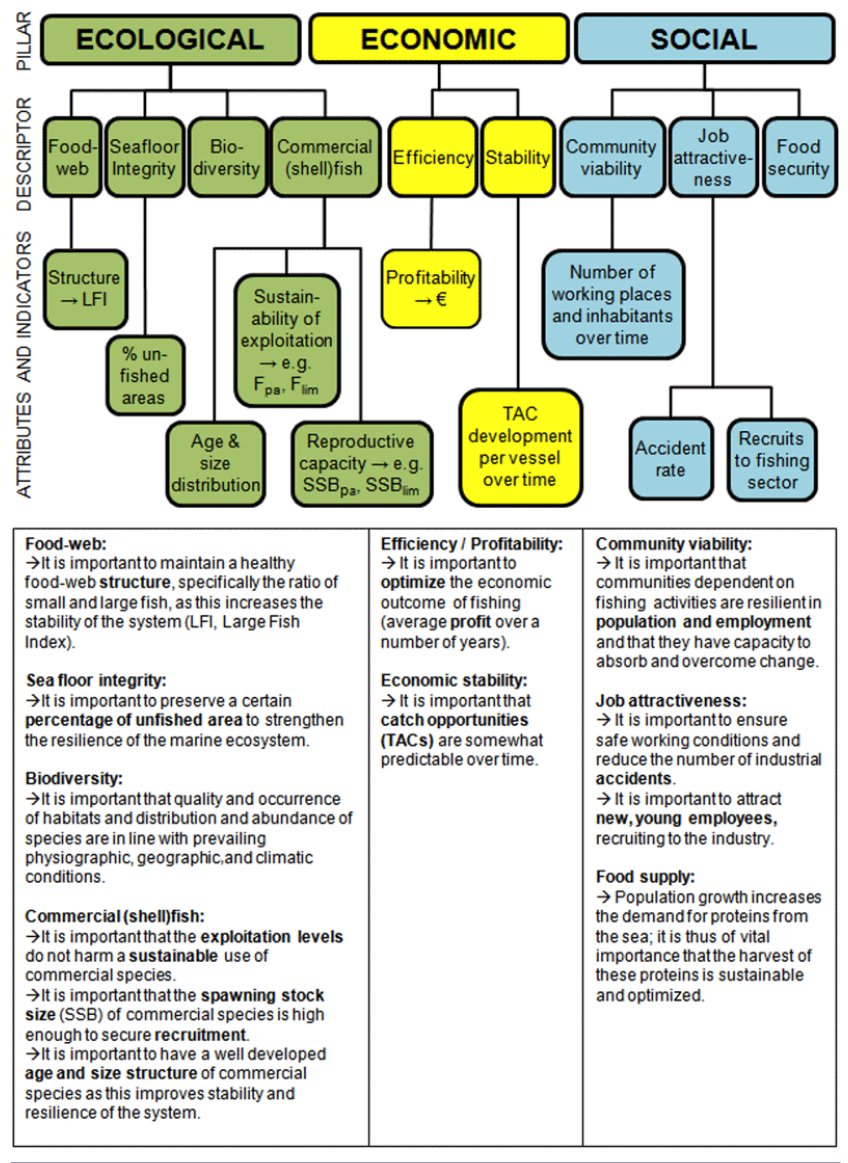

Considering that RACs consisted of representatives from two of the four predefined groups, we targeted the four RACs with geographic relevance for the project: North Sea RAC, North Western Waters RAC, South Western Waters RAC, and the Pelagic RAC. We asked these RACs to send up to five representatives to our workshops. Representatives of national fisheries authorities were drawn from a list of relevant civil servants in charge of fisheries management generated by project partners from each of the countries participating in the project. The project members with a scientific background and their networks was used to generate representatives of the predefined group "fisheries scientists." Finally, employees of DirectorateGeneral for Maritime Affairs and Fisheries and Environment Directorate-General involved in fisheries management were 
invited to participate to ensure that the EU perspective was also represented. Workshop participation lists were reviewed and supplemented when necessary, based on the background variables of nationality and stakeholder group, to ensure a balanced representation from all groups.

As part of the workshops and by the use of a questionnaire (see Appendices 1 and 2), individual data were collected on the importance that stakeholders assigned to each pillar and to each descriptor. Each workshop started with a presentation of the hierarchical tree (Fig. 1) by a member of the MEFEPO project team, which introduced the consistent use of the pillar terms of ecological, economic, and social. All participants had the same introduction to the pillars and descriptors, including the pillar names. The questionnaire asked the respondent for information on professional background, providing the four predefined stakeholder groups, educational background, and nationality. It also asked the participants to assign scores to the three pillars and nine descriptors. Feedback from the first workshop that the questionnaire was a bit "messy" led to a layout change that was applied in the second workshop. Because of low representation of EU authorities in the workshops, we sent the second version of the questionnaire electronically to a few representatives who were dealing with fisheries issues from the Directorate-General for Maritime Affairs and Fisheries and the Directorate-General for the Environment. Five additional questionnaires were received from this electronic survey. Hence, our entire sample consisted of 85 fisheries stakeholders. Figure 2 shows the composition of these 85 stakeholders in terms of professional and educational background.

Fig. 2. Number of stakeholders per professional background (stakeholder group) and educational background.
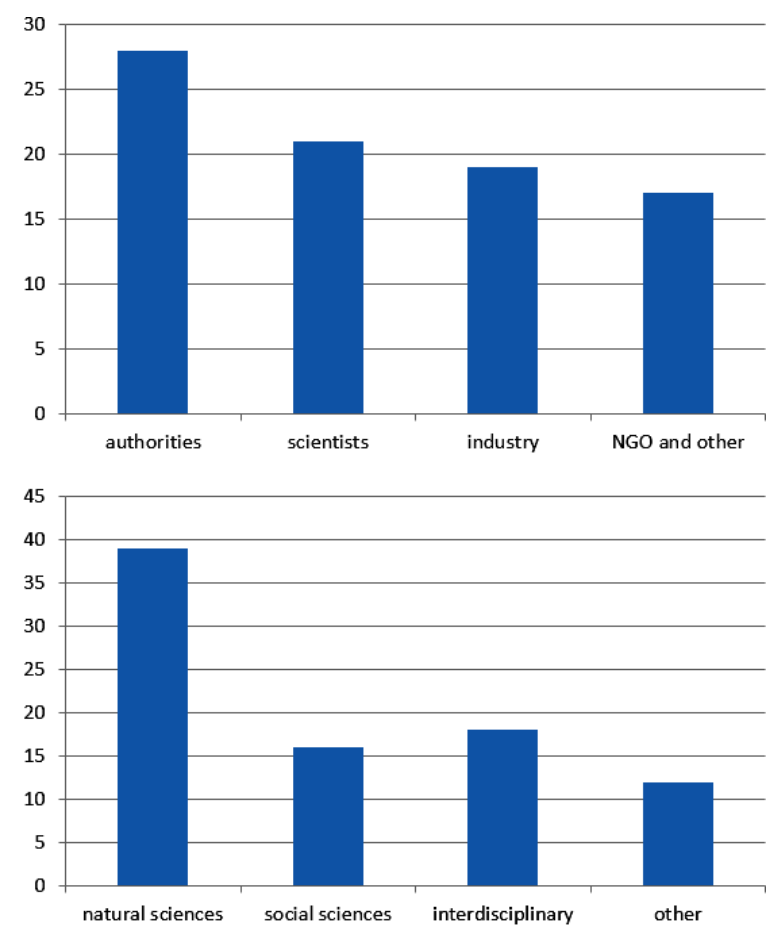

The participants were relatively equally distributed among stakeholder groups, with 28 from national and EU authorities, 21 scientists, 19 from the industry, and 17 from NGOs and others. Regarding educational background, 39 of the respondents studied natural sciences, 16 studied social sciences, and 18 had an interdisciplinary background. A total of 12 stakeholders had other educational backgrounds. We did not inquire further about education, such as level, discipline, and specialization.

The participants were relatively unevenly distributed by nationality, with 5 from France, 6 from Ireland, 7 from Denmark, 8 each from Norway and Spain, 14 from Portugal, 16 from the Netherlands, and 21 from the United Kingdom. In addition, 1 participant was from Canada. Given the recruitment process, our sample was a convenience sample, and statistical representativeness was not a focal point.

\section{Statistical methods}

The questionnaire's main objective was to collect stakeholders' preference scores with respect to (1) the three pillars and (2) the nine descriptors. The participants were asked to distribute a total of 100 points between the 3 pillars and another 100 points among the 9 descriptors. The result was a data set consisting of 85 cases, each with specification of nationality, stakeholder group, and disciplinary background, and with scores on the 3 pillars and 9 descriptors. The variables of nationality, profession, and educational background were categorical. We explored whether these background variables could contribute to explaining the variance in scores on the 3 pillars and the 9 descriptors. Further, we explored whether the pillar scores varied significantly across stakeholder groups. For these purposes we applied an analysis of variance (ANOVA) and Tukey's honest significant differences (Tukey HSDs). The ANOVA indicates whether one-way or twoor three-way differences between groups based on the categorical variables contributed significantly to explaining the variance in the pillar scores. Tukey's HSD test compares the mean of every treatment with the average of every other treatment; i.e., it applies simultaneously to the set of all pairwise comparisons (Crawley 2007). For example, it gave the difference in average score on the ecological pillar between any pair of stakeholder groups, e.g., between authorities and industry, between industry and scientists, between authorities and NGOs, and so on. It simultaneously indicates whether the score difference is significantly different from zero. A Tukey's HSD estimate significantly different from zero indicated that two stakeholder groups at average had a significantly different score on the relevant pillar.

The survey was conducted as part of the two first workshops, and only participants not present in the first workshop filled in the questionnaire during the second workshop. In the third workshop, only participants from the two previous workshops participated. Each workshop started with a presentation of the hierarchical tree as shown in Figure 1, showing the three pillars of sustainable fisheries activities, the ecological, the economic, and the social, and the nine descriptors. This means that all participants got the same introduction to the pillars and descriptors, including the pillar and descriptor names. Also, the project scientists were present during the survey so that the participants could ask the meaning of the different pillar and descriptor terms. Hence, there should be no reason to assume that survey respondents in the first workshop defined and interpreted 
the three pillars and nine descriptors differently from the survey respondents in the second workshop.

\section{RESULTS}

Because the sample consisted of only six representatives from EU authorities, we merged them with national authorities' representatives. Further, we merged representatives from NGOs/ other, so we were left with the four predefined stakeholder groups: authorities, scientists, industry, and NGOs. The educational background also formed four categories: natural science, social science including economics, interdisciplinary, and other. Figure 3 shows the stakeholders' preference scores on the three pillars for each of the four stakeholder groups. The box plots show the median score (bold line), 25th and 75th percentiles (lower and upper box line), and the minimum/maximum value (dashed vertical lines and/or dots; outliers). In the absence of outliers, the vertical dashed lines (whiskers) show the maximum and minimum scores. In the presence of dots, the whiskers give the interquartile range of the scores multiplied by 1.5; the dots give the maximum/ minimum scores, i.e., the outliers. Comparing the upper and lower parts of the boxes indicates the skewness of the data. A larger upper part of the box compared with the lower indicates that the range of higher scores, i.e., above the median, is larger than the range of lower scores (Crawley 2007).

Fig. 3. Box plot of the stakeholders' preference scores for the three sustainability pillars and for each of the stakeholder groups.
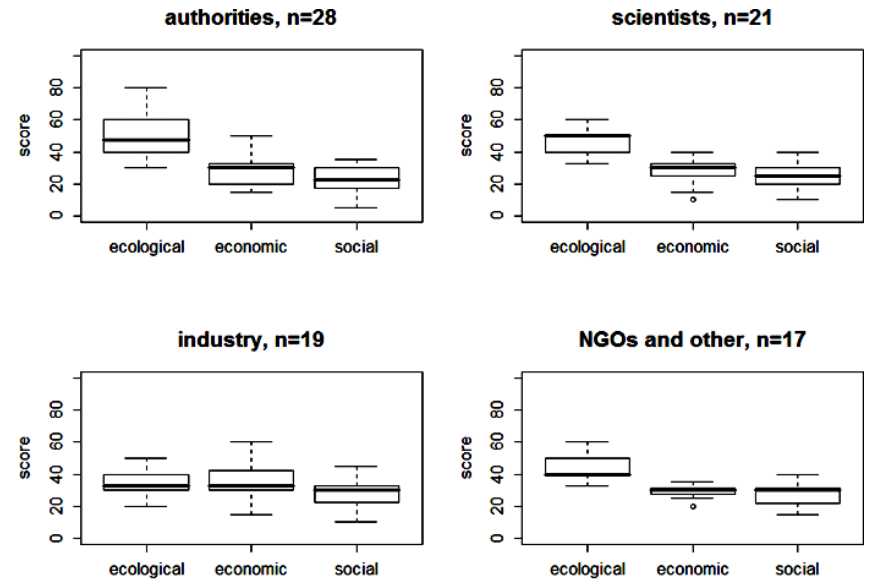

Except for industry, all groups assigned the three pillars similar relative scores, with the ecological pillar ranking first, i.e., the highest preference, and the economic and social pillars following. The industry representatives assigned the ecological and economic pillars equal median (and mean) scores. The authorities, scientists, and industry scored the economic pillar higher than the social one, whereas NGOs scored the two similarly. Authorities are the stakeholder group that most clearly distinguished between the three pillars when appointing scores.

In Appendices 3 and 4, box plots of the stakeholders' preference scores for the three pillars are presented, disaggregated by educational background and nationality. Regarding educational background, the social scientists and interdisciplinary respondents had the clearest differentiation between the three pillars, preferring the ecological to the economic pillar and the economic to the social pillar. Natural scientists and those with other educational background ranked the ecological pillar highest, but gave the economic and social pillars on average equal scores. The pillar scores were not interpreted further by nationality, because for some nations scores were based on very few respondents.

One of the aims of the survey was to find out whether the preferences for the three pillars of sustainable fisheries management varied significantly across stakeholder groups. Figure 3 indicates that industry might differ from the other three predefined groups. With rearrangement of the data, Figure 4 shows the distribution of scores for each stakeholder group on each of the pillars.

Fig. 4. Box plots showing preference scores per sustainability pillar (ecological, economic, social) for each of the four stakeholder groups (authorities, industry, NGO, scientists).
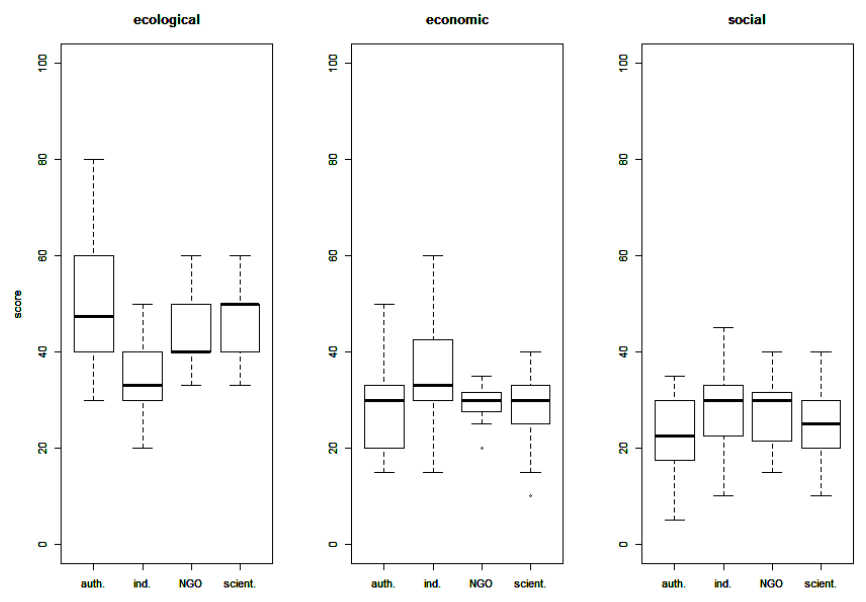

Whereas the scores on the ecological pillar seemed to vary across the stakeholder groups, the scores on the economic pillar seemed to be relatively homogenous across the groups. To find out whether there were significant differences between the stakeholder groups when it came to pillar scores, we applied Tukey's HSD. Figure 5 gives the Tukey's HSD for all pairwise combinations of stakeholder groups for average score on pillars. Difference intervals not overlapping the dotted vertical line imply that the stakeholder groups being compared were significantly different from each other when it came to average pillar score. A difference located on one side of the dotted vertical line means that the difference in average scores between the two stakeholder groups differed from zero, whereas a difference crossing the dotted vertical line means that the difference in average scores between the two stakeholder groups did not differ from zero.

Figure 5 shows that only industry stakeholders differed significantly from representatives of other stakeholder groups. For the ecological pillar, industry representatives had significantly different average scores compared with authorities and scientists, and for the economic pillar they had different average scores compared with all the other groups. For the social pillar, there was no significant difference in average scores between any of the stakeholder groups. 
Table 1. Results from one-way (stakeholder group), two-way (stakeholder group/education), and three-way (stakeholder group/ education/nationality) ANOVA of average pillar scores.

\begin{tabular}{|c|c|c|c|c|c|c|}
\hline & \multicolumn{6}{|c|}{ F-value (significance level in parenthesis) } \\
\hline & \multicolumn{3}{|c|}{ Direct effect } & \multicolumn{2}{|c|}{ Two-way interaction effects } & \multirow{2}{*}{$\begin{array}{c}\text { Three-way interaction effects } \\
\text { Stakeholder:Education: } \\
\text { Nationality }\end{array}$} \\
\hline & Stakeholder & Education & Nationality & $\begin{array}{l}\text { Stakeholder: } \\
\text { Education }\end{array}$ & $\begin{array}{c}\text { Stakeholder: } \\
\text { Nationality }\end{array}$ & \\
\hline \multicolumn{7}{|l|}{ One-way } \\
\hline Ecological & $6.35(* * *)$ & 1.61 & 2.6 & & & \\
\hline Economic & $4.4(* * *)$ & $2.36(*)$ & 0.26 & & & \\
\hline Social & 2.06 & 0.5 & $3.02(*)$ & & & \\
\hline \multicolumn{7}{|l|}{ Two-way } \\
\hline Ecological & $6.28(* * *)$ & 0.6 & & 1.06 & & \\
\hline Economic & $4.65(* * *)$ & 1.72 & & 1.26 & & \\
\hline Social & 1.88 & 0.44 & & 0.18 & & \\
\hline \multicolumn{7}{|l|}{ Two-way } \\
\hline Ecological & $6.67(* * *)$ & & 1.28 & & $2.41(*)$ & \\
\hline Economic & $4.3(* *)$ & & 0.027 & & 0.6 & \\
\hline Social & $2.26(*)$ & & 2.43 & & $3.06(* *)$ & \\
\hline \multicolumn{7}{|l|}{ Three-way } \\
\hline Ecological & $6.5(* * *)$ & 0.62 & 1.28 & 1.09 & $2.44(*)$ & 0.67 \\
\hline Economic & $4.62(* *)$ & 1.71 & 0.001 & 1.76 & 0.58 & 1.13 \\
\hline Social & $2.19(*)$ & 0.52 & 2.65 & 0.31 & $2.8(* *)$ & 1.5 \\
\hline
\end{tabular}

Fig. 5. Ninety-five percent stakeholder group-wise confidence level for difference in mean level of pillar score (Tukey's HSD). The $y$-axis shows the pairwise combinations of stakeholder groups.
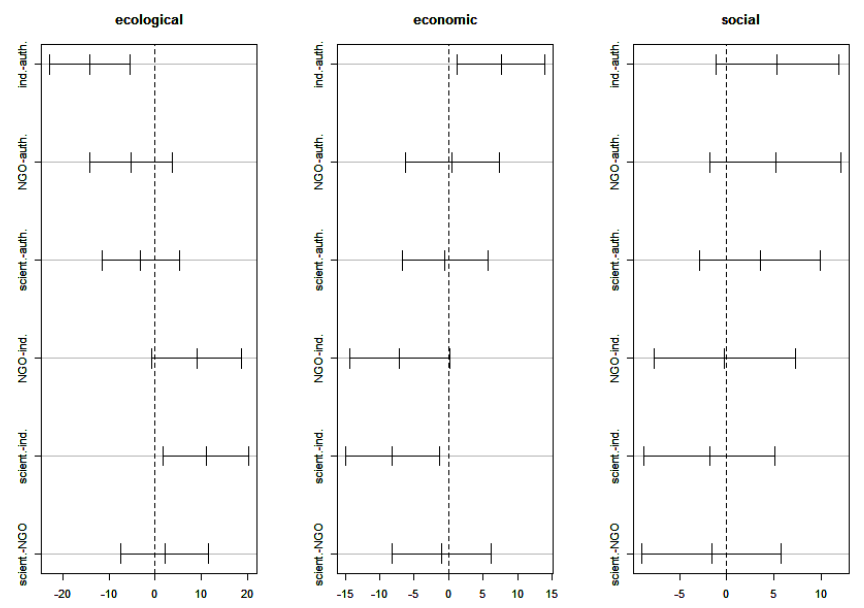

To what degree may the three background variables of stakeholder group (professional affiliation), education (disciplinary background), and nationality contribute to explaining the variance in pillar scores? These results are shown in Table 1. First, running one-way ANOVA for pillar scores with each of the three background variables as the sole explanatory variable showed that stakeholder group explained the variance in pillar scores for the ecological and economic pillars at a 99\% significance level.
Education explained the variance in pillar score for the economic pillar at a $90 \%$ significance level. Nationality explained the variance in pillar score for the social pillar at a $90 \%$ significance level. Note that none of the background variables had significant explanatory power when it came to explaining the variance in average score on all three pillars simultaneously. The reason is that for each respondent the sum of the scores on all pillars should equal 100. Providing high scores on two pillars required low scores on the third. Hence, scores on the three pillars were not independent. To test for possible interaction effects of the three background variables we ran two- and three-way ANOVAs of average pillar scores for each of the pillars.

The two- and three-way ANOVAs showed that nationality reinforced the effect of stakeholder group on the ecological and the social pillar scores. Education, on the other hand, did not affect the relationship between stakeholder group and pillar score significantly, and this was true for all three pillars. None of the three-way effects were significant. The interaction effects between the background variables education and nationality, which are not shown in the table, were not significant. Reversing the interactions, i.e., exploring the effects stakeholder group had on the relationship between pillar score and education, and on the relationship between pillar score and nationality, showed that stakeholder group did reinforce the effects of the two other background variables. However, this effect was not sufficiently strong for education and nationality to become significantly explanatory variables for variances in pillar score when significance was not apparent with the one-way ANOVA.

\section{DEMONSTRATION CASE}

We have shown that although belonging to a specific stakeholder group could significantly explain the variances in scores on the 
pillars, the difference in average score between the stakeholder groups was only minimally significant. Only industry differed significantly from the other three groups when it came to scores on the ecological and economic pillars. In this section we discuss the possible consequences when belonging to a specified stakeholder group is the criterion for appointment to an advisory position. We use appointment of members to the Regional Advisory Councils (RACs) under the CFP as an empirical example.

The executive committee of each RAC, which is the body with the final say in input to EU fisheries authorities, has a limit of 24 members; a maximum of two-thirds of these should be representatives from the industry and the remaining one-third should be representatives from organizations, including ENGOs, organizations for community and fishers' welfare, and sports and recreational organizations (Council of the European Union 2004). The representatives from organizations are not allowed to have economic interests in the fisheries. The general assembly approves each of the 24 representatives. The representatives are nominated by organizations, and in theory all organizations claiming a stake in fisheries activities may nominate a representative. In reality, it is the larger organizations that get seats on the executive committee. When approved, a representative is appointed for three years. All organizations may attend working groups that give input to the executive committee. All nations with fishing activities in the seas encompassed by the RAC should be equally represented.

Not involving other stakeholder groups implies that the EU and national authorities' preferences will be predominant in fisheries management decisions. Figure 6 shows the average score on the pillars for the four predefined stakeholder groups.

Fig. 6. Average scores on the pillars for the stakeholder groups.

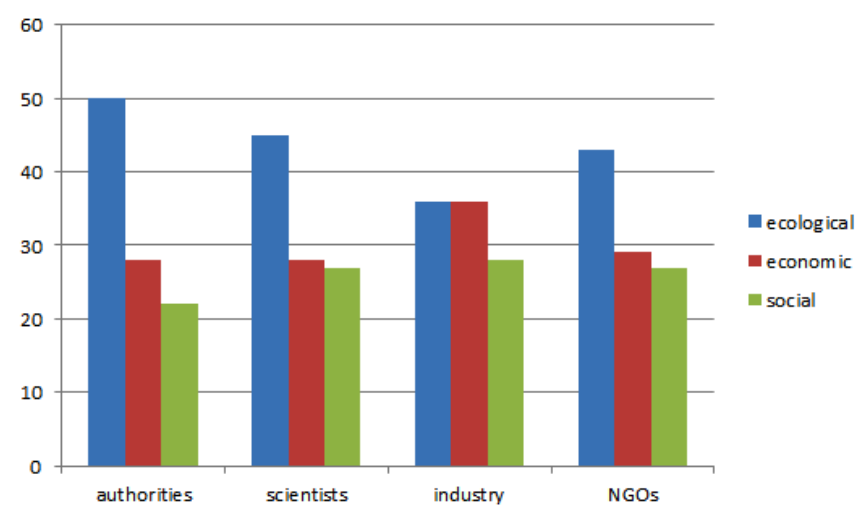

We assumed that the representatives of a RAC executive committee would be selected from the industry and NGO participants in our survey. Because there were only 19 participants from the industry, we built test committees consisting of 12 instead of 24 members. Although that is only $50 \%$ of the original size, it still allowed for some randomness in the selection of industry representatives in the test committee. We drew 8 representatives from the industry stakeholder group and 4 from the NGO/other stakeholder groups. We made 20 random draws of representatives to the test committee. The average pillar scores for each of the randomly drawn test committees are given in Figure 7.

Fig. 7. Average committee score on the pillars for 20 randomly drawn Regional Advisory Council (RAC) executive committees with 8 industry representatives and 4 NGO representatives.

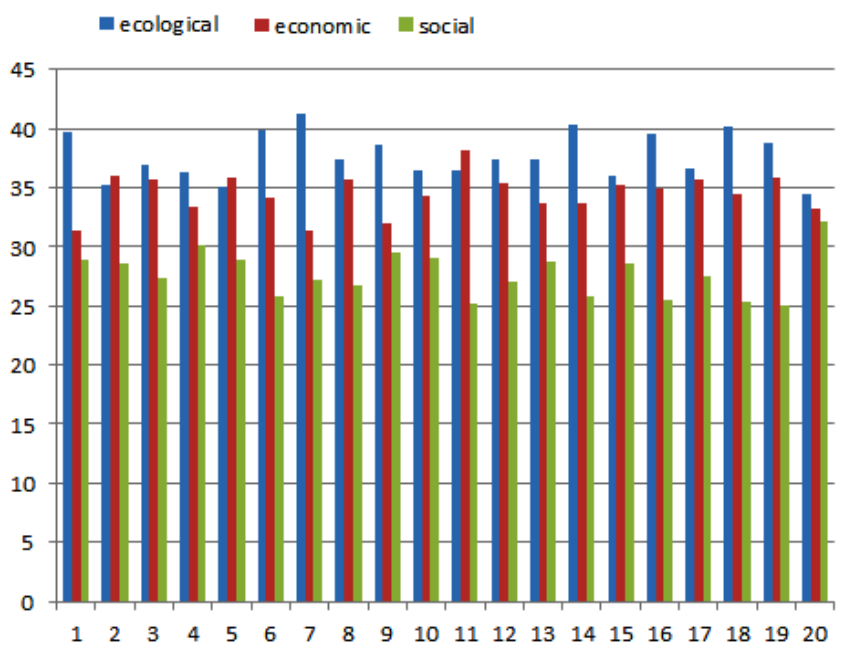

Figure 7 shows possible preferences among the three pillars of sustainable fisheries activities for hypothetical RAC executive committees consisting of 12 members, 8 representatives from the industry and 4 from NGOs/other. First, it is clear that the preferences of the authorities (see Fig. 6) cannot be replicated by these randomly chosen RAC committees. This is good news because the intention of the RACs has been to take into consideration preferences other than those of the fisheries authorities. This result implies that basing fisheries management on the advice of the RAC would change the management compared with a situation in which the fisheries authorities, whether at the EU or national level, are the sole regulator. Second, some group scores, e.g., those of groups 2, 5, and 17, are quite similar to the scores of the industry stakeholder group. However, no groups had scores resembling those of the stakeholder group described as NGO/other. Of course, this may be because of the specific composition of that group in our data set. In general, the one-third of the RAC representatives from NGOs and other organizations would probably be more heterogenous and their preferences more dependent on the selection of organizations present in each specific RAC.

With the present composition of the RAC executive committee, the RAC's preferences among the three pillars of sustainable fisheries activities could be the same as those of a committee consisting solely of industry representatives. Another combination of organization representatives might give the same result for the $\mathrm{NGO} /$ other stakeholder group. However, because that stakeholder group counts for only one-third of the committee members, this is less likely. The economic pillar was scored more highly than the ecological pillar by 2 of the 3 groups ( 2 and 5, but not 17 ) that had preferences resembling those of the industry 
stakeholder group. This is far from the preference structure of any of the other 3 stakeholder groups: authorities, scientists, and NGOs/other.

These results are indicated by the Tukey's HSD shown in Figure 5. Except for industry, there were no significant differences in average pillar score among the stakeholder groups. Industry, on the other hand, differed significantly from authorities and scientists when it came to the average score on the ecological and economic pillars, and from NGOs on the economic pillar. In an extreme case, it would be possible to have a RAC executive committee that expresses almost the same preferences as the industry stakeholder group. The same is less likely for other stakeholder groups.

\section{DISCUSSION AND CONCLUSION}

Representatives from different stakeholder groups do not necessarily have different preferences regarding fisheries objectives. Although stakeholder group was identified as a significant background variable in explaining average score on each of the pillars separately, only preferences of the industry representatives differed significantly from those of representatives in other stakeholder groups based on differences in average scores on the ecological and economic pillars. For all other groups there were no significant differences in average pillar scores. There were no significant differences in average score for the social pillar among the four predefined stakeholder groups: authorities, scientists, industry, and NGOs/other. The results support those from previous surveys that show that there is substantial agreement across stakeholder groups on fisheries objectives, but a lack of coherence within predefined stakeholder groups (Mardle et al. 2004, Wattage et al. 2005, Pascoe et al. 2009)

The 2002 reform of the CFP and the proposition paper on the 2012 reform both emphasize the importance of including a broader set of fisheries stakeholders in the management process. The 2002 reform introduced RACs (Council Regulation 2002) with representatives from the industry and other organizations including NGOs, sport clubs, fishers' welfare organizations, and community organizations; and the 2012 reform stressed the importance of giving the fishing industry greater influence in and responsibility for fisheries management (Commission of European Communities 2009). The idea behind the establishment of the RACs is that greater stakeholder involvement will bring in a larger variety of interests and expertise from the field, connected to fisheries activities, thus giving the fisheries management greater legitimacy (Arnstein 1969, Raakjær and Vedsmand 1995, Degnbol et al. 2006, de Vos and Tatenhove 2011, Linke et al. 2011, Phillipson and Symes 2013). However, one may question whether the composition of the RACs, based on belonging to one of two predefined stakeholder groups, i.e., industry and NGOs, secures a broader representation of preferences.

Our survey demonstrates that industry representatives have significantly different preferences for the ecological, economic, and social pillars of sustainable fisheries than representatives from the other three stakeholder groups: authorities, scientists, and NGOs/other. If the recommendations of the RACs, which are two-thirds industry, are ratified by the EU and formally incorporated into management, there would be different priorities for fisheries management than there would be if management were developed solely by national and EU authorities. Industry dominance of the RACs and the significant heterogeneity in the preferences of the NGOs, possibly because of the breadth of interests represented, from fishers' welfare organizations to bird watchers, could mean that nonindustry views may not be well represented in the recommendations put forward to the EU. However, the expectation of the RAC process is that deliberation among groups should lead to consensus and thus to recommendations that are supported by all RAC members.

However, this does not mean that the views of non-RAC stakeholders, individually or as a group, are well represented in recommendations going forward. The preferences of 20 randomly drawn RAC committees consisting of 8 industry and 4 NGO representatives from our survey participants (to reflect the fact that RACs consist of two-thirds industry and one-third NGO representatives) were examined based on average pillar score. Only 3 of the 20 committees generated preferences similar to those of the industry stakeholder group and none of the committees' preferences resembled those of the NGO stakeholder group. This indicates that consensus may be heavily influenced by the individuals selected to represent stakeholder groups; thus, management is as much about who represents the different stakeholder groups as it is about which stakeholder groups are represented. However, in this study we could not determine whether the similarities in preferences were because of learning and interaction within RACs or other common institutions, or whether they were prior preferences. More qualitative data on stakeholder groups and interactions are needed to identify power structures within the RACs, interactions among stakeholders, and the internal negotiating processes they use. Exploring the why and how of these similarities and differences in preferences, and the consequences for the resultant fisheries management, is an interesting subject for future work.

Our results may, however, have implications for stakeholder involvement in fisheries management in terms of the selection of representatives for the different stakeholder groups, and the inclusion of new or more stakeholders and/or stakeholder groups in the future. The current RAC construction, two-thirds industry and one-third NGO/other, implies that the breadth of interests represented may be smaller than what was originally intended. Our results demonstrate that the selection of representatives to be involved in fisheries management based only on our predefined stakeholder groups may not be appropriate. The fact that preferences may not be group specific, but rather individual, poses a challenge for representation for all those involved in fisheries management and raises questions about whether representatives could or should be selected individually, e.g., through a referendum-like process or random sampling, rather than as members of a particular group. This approach obviously comes with its own challenges: For example, who should assess the individuals and what preferences should be the basis of the assessment? However, the priority should be to clarify what preferences, group and/or individual, should be considered within fisheries management. Given that there is not sufficient time or money to have everyone involved, the challenge is how to effectively enhance mechanisms for dialogue to reach consensus, taking account of the preferences and targets for sustainable fisheries.

We applied quantitative measures to describe preferences and analyze to what degree fisheries stakeholder groups differ when it comes to prioritizing ecological, economic, and social aspects 
of fisheries management. However, the influence that these different groups have on the decision-making process of fisheries management is outside the scope of this paper. Of the four stakeholder groups, i.e., authorities, scientists, NGOs/other, and industry, the only group that significantly distinguishes itself is the industry sector. The fact that authorities, scientists, and NGOs/other agree that an ecologically focused approach should be adopted, whereas industry rates economic aspects just as highly, is interesting and may have consequences once the revised 2012 CFP has been properly implemented. The revised CFP suggests that industry get more involved in the management of the fisheries. At the same time, an ecosystem-based approach to fisheries management is set up as a goal to work toward. Given that the industry stakeholder group in our survey put the lowest weight of all the stakeholder groups on the ecological aspect of fisheries management, one might suspect that the 2012 revision of the CFP could lead to inconsistencies. On the other hand, although the industry group on average rated the ecological aspect lower than the other stakeholders groups, they ranked economic and ecological aspects of fisheries management equally high, and higher than social aspects. Hence, giving industry a greater say in fisheries management probably implies that there will be a move toward management plans that seek to balance ecological and economic aspects of fisheries management, compared with a more unilateral focus on ecological aspects, which according to our results, especially the authorities represent. The implications of our results when combined with the weight of present and future voices in European fisheries management are left for future research.

Responses to this article can be read online at: http://www.ecologyandsociety.org/issues/responses. $\mathrm{php} / 6947$

\begin{abstract}
Acknowledgments:
The survey on which this paper is based was conducted as part of the EC-FP7 funded project Making the European Fisheries Ecosystem Plan Operational (MEFEPO; Project \# 212881), coordinated by the University of Liverpool, Liverpool, UK (www. liv.ac.uk/mefepo). We wish to thank all stakeholders who took part in the survey, and all of the researchers involved in the MEFEPO project for very valuable discussions and input, without which we would not have been able to write the paper. We also wish to thank two anonymous referees for insightful comments that have contributed to make the paper more accurate, relevant, and interesting. All viewpoints and eventual errors are the responsibility of the authors.
\end{abstract}

\section{LITERATURE CITED}

Arnstein, S. R. 1969. A ladder of citizen participation. Journal of the American Institute of Planners 35:216-224. http://dx.doi. org/10.1080/01944366908977225

Berkes, F., J. Colding, and C. Folke. 2000. Rediscovery of traditional ecological knowlede as adaptive management. Ecological Applications 10:1251-1262. http://dx.doi.org/10.1890/1051-0761 (2000)010[1251:ROTEKA]2.0.CO:2
Commission of European Communities. 2009. Reform of the Common Fisheries Policy. Green Paper No. 163. Brussels, 22.4.2009; $\operatorname{COM(2009)163~final.~Commission~of~European~}$ Communities, Brussels, Belgium. [online] URL: http://eur-lex. europa.eu/LexUriServ/LexUriServ.do?uri=COM:2009:0163:FIN: EN:PDF

Council of the European Union. 2004. Council decision 2004/585/ EC establishing Regional Advisory Councils under the Common Fisheries Policy. Official Journal of the European Union 256:17-22. [online] URL: http://faolex.fao.org/cgi-bin/faolex.exe? rec id $=036493 \&$ database=faolex\&search $\_$type $=$link \&table=result\&lang $=$ eng\&format name $=@$,ERALL

Crawly, M. J. 2007. The R book. Wiley, Chichester, UK.

Davis, A., and J. Wagner. 2003. Who knows? On the importance of identifying "experts" when reaching local ecological knowledge. Human Ecology 31:463-489 http://dx.doi.org/10.1023/ A:1025075923297

de Nooy, W. 2013. Communication in natural resource management: agreement between and disagreement within stakeholder groups. Ecology and Society 18(2): 44. http://dx.doi. org/10.5751/ES-05648-180244

de Vos, B. I., and J. P. M. van Tatenhove. 2011. Trust relationships between fishers and government: new challenges for the comanagement arrangements in the Dutch flatfish industry. Marine Policy 35:218-225. http://dx.doi.org/10.1016/j.marpol.2010.10.002

Degnbol, P., H. Gislason, S. Hanna, S. Jentoft, J. R. Nielsen, S. Sverdrup-Jensen, and D. Clyde Wilson. 2006. Painting the floor with a hammer: technical fixes in fisheries management. Marine Policy 30:534-543. http://dx.doi.org/10.1016/j.marpol.2005.07.002

European Union (EU). 2002. Council Regulation (EC) No 2371/2002 of 20 December 2002 on the conservation and sustainable exploitation of fisheries resources under the Common Fisheries Policy. Official Journal of the European Union 358:59-80. [online] URL: http://eur-lex.europa.eu/legal-content/EN/TXT/? uri=uriserv:OJ.L .2002.358.01.0059.01.ENG

European Union (EU). 2013. Regulation (EU) No 1380/2013 of the European Parliament and of the Council of 11 December 2013 on the Common Fisheries Policy, amending Council Regulations (EC) No 1954/2003 and (EC) No 1224/2009 and repealing Council Regulations (EC) No 2371/2002 and (EC) No 639/2004 and Council Decision 2004/585/EC. Official Journal of the European Union 354:22-61. [online] URL: http://eur-lex. europa.eu/LexUriServ/LexUriServ.do?uri=OJ:L:2013:354:0022:0061: EN:PDF

Gasalla, M. A., and A. C. S. Diegues. 2011. People's seas: “ethnooceanography" as an interdisciplinary means to approach marine ecosystem change. Pages 120-136 in R. Ommer, I. Perry, K. L. Cochrane, and P. Cury, editors. World fisheries: a social-ecological analysis. Wiley-Blackwell, Oxford, UK.

Haapasaari, P., S. Mäntyniemi, and S. Kuikka. 2013. Involving stakeholders in building integrated fisheries models using Bayesian methods. Environmental Management 51(6):1247-1261. http://dx.doi.org/10.1007/s00267-013-0041-9

Hatchard, J. 2005. Engaging stakeholder preferences through deliberative democracy in North Sea fisheries governance. Pages 
45-64 in T. S. Grey, editor. Participation in fisheries governance. Springer Netherlands, Dordrecht, The Netherlands. http://dx. doi.org/10.1007/1-4020-3778-3 3

Leslie, H. M., and K. L. McLeod. 2007. Confronting the challenges of implementing marine ecosystem-based management. Frontiers in Ecology and the Environment 5:540-548. http://dx.doi. org/10.1890/060093

Link, J. I. 2002. What does ecosystem based fisheries management mean? Fisheries 27:18-21.

Linke, S., M. Dreyer, and P. Sellke. 2011. The Regional Advisory Councils: what is their potential to incorporate stakeholder knowledge into fisheries governance? AMBIO 40:133-143. http:// dx.doi.org/10.1007/s13280-010-0125-1

Mackinson, S., D. C. Wilson, P. Galiay, and B. Deas. 2011. Engaging stakeholders in fisheries and marine research. Marine Policy 35:18-24 http://dx.doi.org/10.1016/j.marpol.2010.07.003

Mardle, S., S. Pascoe, and I. Herrero. 2004. Management objective importance in fisheries: an evaluation using the analytic hierarchy process (AHP). Environmental Management 33:1-11. http://dx. doi.org/10.1007/s00267-003-3070-y

Nielsen, J. R., and C. Mathiesen. 2006. Stakeholder preferences for Danish fisheries management of sand eel and Norway pout. Fisheries Research 77: 92-101 http://dx.doi.org/10.1016/j. fishres.2005.08.002

Pascoe, S., W. Proctor, C. Wilcox, J. Innes, W. Rochester, and N. Dowling. 2009. Stakeholder objective preferences in Australian Commonwealth managed fisheries. Marine Policy 33:750-758 http://dx.doi.org/10.1016/j.marpol.2009.02.008

Phillipson, J., and D. Symes. 2013. Science for sustainable fisheries management: an interdisciplinary approach. Fisheries Research 139:61-64. http://dx.doi.org/10.1016/j.fishres.2012.09.012

Piet, G., C. Röckmann, M. Aanesen, C. Armstrong, W. L. Quesne, H. J. Bloomfiled, R. V. Hal, C. Nolan, F. Velasco, M. F. Borges, C. Porteiro, M. P. Rui, C. Hily, J. Duchene, and C. Fried. 2011. Development and selection of operational management strategies to achieve policy objectives, Making the European Fisheries Ecosystem Plan Operational (MEFEPO). Work Package 5 Report. University of Liverpool, Liverpool, UK. [online] URL: http://www.liv.ac.uk/media/livacuk/mefepo/pdf/WP5 TechnicalReport Final.pdf

Raakjær J. N., and T. Vedsmand. 1995. Fisheries co-management: an alternative strategy in fisheries - cases from Denmark. An issue paper for the OECD study on the efficient management of living marine resources. Pages 90-121 in Towards sustainable fisheries: issue papers. Organisation for Economic Co-operation and Development, Paris, France. [online] URL: http://www.oecd. org/officialdocuments/publicdisplaydocumentpdf/?doclanguage $=$ $\underline{\text { en } \& \text { cote }=\text { ocde } / g d(97) 54}$

Rice, J. 2011. Managing fisheries well: delivering the promises of an ecosystem approach. Fish and Fisheries 12:209-231. http://dx. doi.org/10.1111/j.1467-2979.2011.00416.x

Röckmann, C., C. Ulrich, M. Dreyer, E. Bell, E. Borodzicz, P. Haapasaari, K. H. Hauge, D. Howell, S. Mäntyniemi, D. Miller, and M. Pastoors. 2012. The added value of participatory modelling in fisheries management-what has been learnt? Marine Policy 36:1072-1085. http://dx.doi.org/10.1016/j. marpol.2012.02.027

Röckmann, C., J. van Leeuwen, D. Goldsborough, M. Kraan, and G. Piet. 2015. The interaction triangle as a tool for understanding stakeholder interactions in marine ecosystem based management. Marine Policy, in press.

Townsley, P. 1998. Stakeholder groups. In Social issues in fisheries. FAO Fisheries Technical Paper 375. Food and Agriculture Organization of the United Nations, Rome, Italy. [online] URL: http://www.fao.org/docrep/003/W8623E/w8623e00.HTM

Wattage, P., S. Mardle, and S. Pascoe. 2005. Evaluation of the importance of fisheries management objectives using choice experiments. Ecological Economics 55:85-95. http://dx.doi. org/10.1016/j.ecolecon.2004.10.016

Wiber, M., F. Berkes, A. Charlesc, and J. Kearney. 2004. Participatory research supporting community-based fishery management. Marine Policy 28:459-468 http://dx.doi.org/10.1016/ j.marpol.2003.10.020 
Appendix 1. Survey questionnaire, first workshop.

Background information

\begin{tabular}{|c|c|c|}
\hline \multicolumn{3}{|l|}{ Nationality } \\
\hline Disciplinary background & \multicolumn{2}{|c|}{ Professional background } \\
\hline - natural sciences & -policy & \\
\hline -social sciences & -science & \\
\hline -economics & -industry & \\
\hline -interdisciplinary & -NGO & \\
\hline -other & -other & \\
\hline
\end{tabular}

Please assign a weight between $0-100$ to each of the descriptors, such that the weights sum up to 100

\begin{tabular}{|l|l|}
\hline Indicator & Weight \\
\hline - foodweb & \\
\hline -sea floor integrity & \\
\hline - biodiversity & \\
\hline -commercial fish & \\
\hline - efficiency & \\
\hline -stability & \\
\hline -community viability & \\
\hline -job attractiveness & \\
\hline - food security & 100 \\
\hline Sum & \\
\hline
\end{tabular}


Background information

\begin{tabular}{|c|c|c|}
\hline Nationality & & \\
\hline Disciplinary backg & Professior & ound \\
\hline -natural sciences & -policy & \\
\hline - social sciences & -science & \\
\hline -economics & -industry & \\
\hline - interdisciplinary & $-N G O$ & \\
\hline -other & -other & \\
\hline
\end{tabular}

Please assign a weight between 0-100 to each of the pillars, such that the weights sum up to 100

\begin{tabular}{|l|l|}
\hline Pillar & Weight \\
\hline Ecological & \\
\hline Economic & \\
\hline Social & \\
\hline Sum & 100 \\
\hline
\end{tabular}


Appendix 2. Survey questionnaire, second workshop. This is the second page of the questionnaire. The first page of the questionnaire contains the hierarchical tree shown in Figure 1 in the manuscript.

How important are environmental, economic and social aspects in fisheries management?

From your personal point of view please assign a weight between 0-100 to each of the pillars, such that the weights sum up to 100

\begin{tabular}{|l|c|}
\hline Pillar & Weight \\
\hline Ecology & \\
\hline Economy & \\
\hline Social & \\
\hline Sum & $\mathbf{1 0 0}$ \\
\hline
\end{tabular}

Please assign a weight between 0-100 to each of the descriptors, such that the weights sum up to 100

\begin{tabular}{|l|l|}
\hline Descriptor & Weight \\
\hline - foodweb & \\
\hline - sea floor integrity & \\
\hline - biodiversity & \\
\hline - commercial fish & \\
\hline - efficiency & \\
\hline - stability & \\
\hline - community viability & \\
\hline - job attractiveness & \\
\hline - food security & \\
\hline Sum & $\mathbf{1 0 0}$ \\
\hline
\end{tabular}

\section{Background information}

Nationality:

\begin{tabular}{|l|l|l|l|}
\hline \multicolumn{2}{|l|}{ Disciplinary background } & \multicolumn{2}{|l|}{ Professional background } \\
\hline - natural sciences & - policy & \\
\hline - social sciences & & - science & \\
\hline - economics & & - industry & \\
\hline - interdisciplinary & - NGO & \\
\hline - other & - other & \\
\hline
\end{tabular}


Appendix 3. Pillar scores as divided on educational background
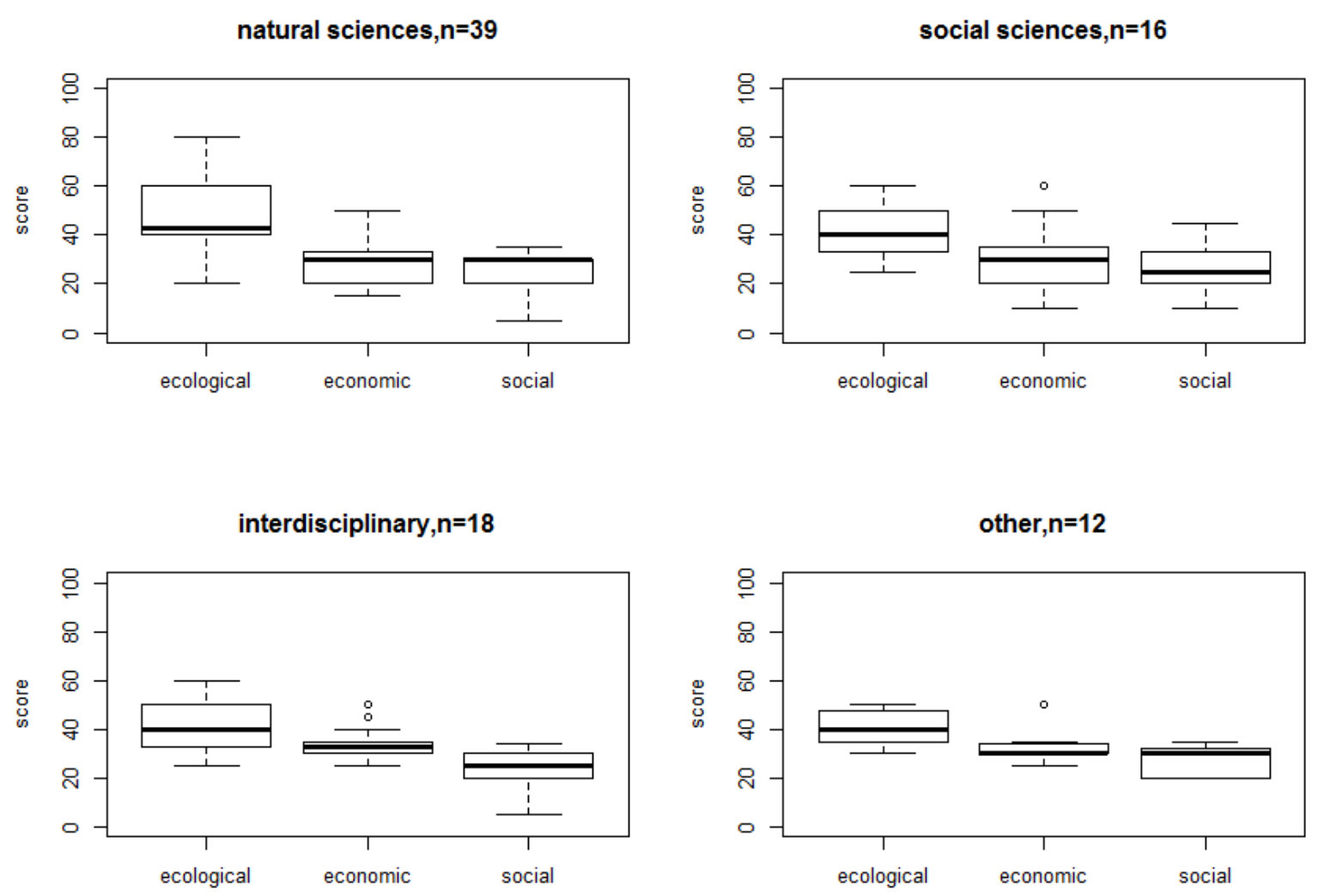
Appendix 4. Pillar scores as divided on nationality

Portugal, $n=14$

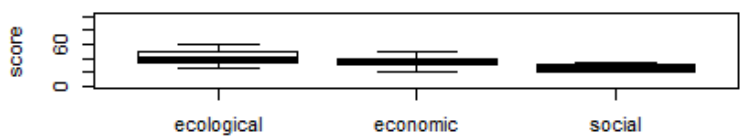

Netherland, $n=16$

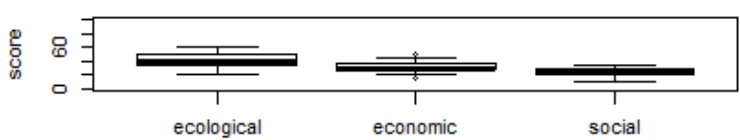

UK, $n=21$

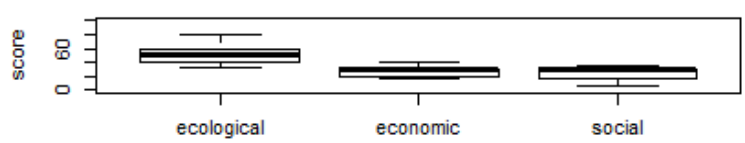

Norway, $n=8$

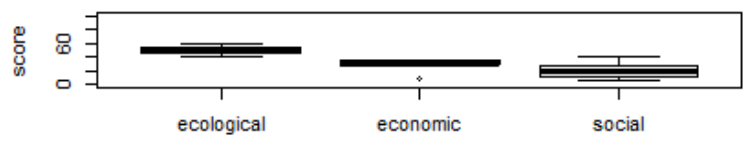

France, $n=5$

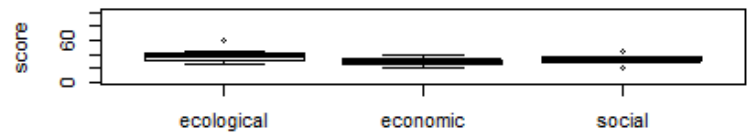

Ireland, $\mathrm{n}=6$

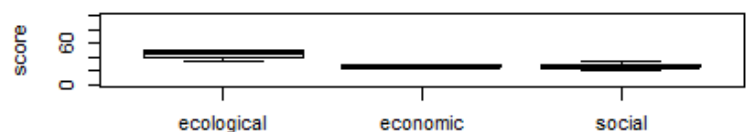

Denmark, $\mathbf{n}=7$

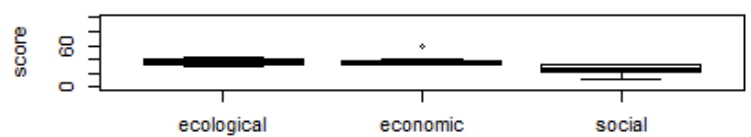

